\title{
Reasons Older Veterans Use the Veterans Health Administration and Non-VHA Care in an Urban Environment
}

\author{
Matthew R. Augustine, MD, Tanieka Mason, MPH, Abigail Baim-Lance, PhD, and
} Kenneth Boockvar, MD

Background: Older veterans in urban settings rely less on the Veterans Health Administration (VHA) health care, suggesting deficits of access and services for aging veterans. We aimed to identify reasons for VHA and non-VHA use across the health status of older, urban-dwelling veterans.

Methods: We examined open-ended responses from 177 veterans who were enrolled in primary care at the Bronx VA Medical Center, used non-VHA care in prior 2 years, and completed baseline interviews in a care coordination trial from March 2016 to August 2017. Using content analysis, we coded and categorized key terms and concepts into an established access framework. This framework included 5 categories: acceptability (relationship, second opinion), accessibility (distance, travel); affordability; availability (supply, specialty care); and accommodation (organization, wait-time). Selfreported health status was stratified by excellent/very good, good, and fair/poor.

Results: We were able to categorize the responses of 166 veterans, who were older $(\geq 75$ years, $61 \%)$, minority race and ethnicity $(77 \%)$, and low income $(<\$ 25,000 / y, 51 \%)$. Veterans mentioned acceptability (42\%) and accessibility (37\%) the most, followed by affordability (33\%), availability (25\%), and accommodation (11\%). With worse self-reported health status, accessibility intensified (excellent/very good, $24 \%$; fair/poor, $46 \% ; P=.031$ ) particularly among minority veterans, while acceptability remained prominent (excellent/very good, $49 \%$; fair/poor, $37 \% ; P=.25$ ). Other categories were mentioned less with no significant difference across health status.

Conclusions: Even in an urban environment, proximity was a leading issue with worse health. Addressing urban accessibility and coordination for older, sicker veterans may enhance care for a growing vulnerable VHA population. (J Am Board Fam Med 2021;34:291-300.)

Keywords: Access to Health Care, Aging, Geriatrics, Health Status, Military Medicine, Qualitative Research, Urban Population, Primary Health Care, Veterans Health Administration

\section{Introduction}

Older adults with declining health face increasing challenges in health system navigation and access.

This article was externally peer reviewed.

Submitted 30 June 2020; revised 3 November 2020; accepted 3 November 2020.

From the Geriatric Research Education and Clinical Center (GRECC), James J Peters VA Medical Center, Bronx, NY (MRA, TM, AB-L, KB); Icahn School of Medicine at Mount Sinai, Department of Medicine, New York, NY (MRA); Icahn School of Medicine at Mount Sinai, Department of Geriatrics and Palliative Medicine, New York, NY (AB-L, KB); Community Wellness Department, Reading Hospital, Reading, PA (TM); Research Institute on Aging, The New Jewish House, New York, NY (KB).

Funding: This research was funded by and supported by Merit Review Award Number I01 HX001563 from the US Department of Veterans Affairs (VA) Health Services
The Veterans Health Administration (VHA) health care system is the largest integrated health system in the United States, caring for more than 7 million patients with nearly half over the age of 65 years. More than $90 \%$ of veterans enrolled in VA older than 65 are also covered by Medicare. ${ }^{1}$ Prior evidence suggests that veterans shift care to non-VHA sources as they age, develop greater medical complexity, acquire a disability, must travel greater distances, and reside in urban environments with

Research \& Development Service of the VA Office of Research and Development.

Conflict of interest: All authors report none.

Corresponding author: Matthew R. Augustine, MD, James J. Peters VA Medical Center, 130 W Kingsbridge Road, Bronx, NY 10468 (E-mail: matthew.augustine2@va.gov). 
competing sources of care. ${ }^{2-4}$ While this dual use of VHA and non-VHA health care may enhance access, the unintended consequences of fragmentation ${ }^{5}$ and lack of continuity may lead to adverse events and outcomes. ${ }^{6-10}$ Understanding why older veterans choose VHA or non-VHA care could inform ways to maintain and improve the quality of care for an aging and particularly vulnerable veteran population.

Recent evidence suggests that older veterans are increasingly relying on the VHA than privatesector alternatives to fill their health care needs. ${ }^{11}$ The VHA delivers high-quality care, meeting and exceeding the private sector ${ }^{12}$ by using multidisciplinary care teams dedicated to providing comprehensive and coordinated primary ${ }^{13,14}$ and geriatric care. ${ }^{15}$ However, adequate access to and availability of VHA services remains a concern. Only $42 \%$ of veterans over the age of 65 years who are enrolled in VHA report that the VHA fulfills most or all their needs. ${ }^{1}$ To address this issue, veterans who face wait times exceeding 20 days and 28 days or travel times exceeding 30 minutes and 60 minutes for primary care and specialty services, respectively, qualify to use nonVHA services without the need for Medicare or private sector insurance coverage. ${ }^{16}$ Nearly $30 \%$ of all VHA care is provided by non-VHA providers through this benefit. ${ }^{17}$ The MISSION $\mathrm{Act}^{16}$ aims to further enhance access to non-VHA services for urgent and specialty care. For younger, less complex patients, enhanced access to care outside the VHA may result in timely treatment and outcomes; ${ }^{18}$ however, for the socioeconomically disadvantaged and more complex veteran population who typically relies on VHA for all services, ${ }^{12,19}$ the benefits of enhanced timeliness to care may be superseded by the unintended consequences of care fragmentation. ${ }^{5,8}$

This analysis examines survey responses of veterans over the age of 65 years who get primary care at the James J Peters VA Medical Center in the Bronx, NY (Bronx VAMC) and have previously used non-VHA services (dual system use). We examined the reasons for dual system use across levels of self-reported health. As the VHA aims to expand choice and access, the number of veterans obtaining care from non-VHA sources is likely to increase. This study aims to further elucidate reasons for dual non-VHA and VHA use for older veterans with poorer self-reported health.

\section{Methods}

\section{Study Design and Population}

Researchers analyzed responses to a baseline survey from an ongoing coach-delivered care transitions trial, which leverages Health Information Exchange to enhance care coordination and transitions. ${ }^{20}$ The study population included veterans who were over 65 years of age, enrolled and assigned a primary care provider at the James J Peters VA Medical Center (Bronx VAMC) in the Bronx, NY, and have previously used non-VHA services in the Bronx in the prior 2 years. Non-VHA utilization was identified within the Bronx Region Health Information Organization, a health information exchange that contains health care information from the major health systems in the Bronx designed to facilitate care coordination and patient safety. ${ }^{21}$ This study includes responses from the baseline survey of the first 177 patients enrolled from March of 2016 to August 2017. This study, along with informed consent documents, questionnaires, and data collection templates, were approved by the Institutional Review Board of the Bronx VAMC (Protocol BOO-15 to 035 ).

\section{Data Source}

A single research assistant delivered the survey face-to-face or by phone at the time of enrollment to veterans who agreed to participate in the study. The survey included 7 sections and 50 questions: Patient and Residence characteristics $(\mathrm{n}=15)$, care provider and access information $(\mathrm{n}=7)$, insurance coverage and income information $(n=4)$, activities of daily living $(\mathrm{n}=6)$, Instrumental activities of daily living $(\mathrm{n}=7)$, and Short Portable Mental Status Questionnaire (SPMSQ) $(\mathrm{n}=11)$. The duration of the survey took less than 1 hour to complete. All participants received $\$ 25$ in direct deposit to a bank account or in coupons to the hospital store.

In the survey's second section of care provider and access, the research assistant asked participants the opened-ended question: "What are the reasons for using both non-VHA and VHA care?" The same researcher recorded the answers verbatim. The question was repeated if the patient did not respond or understand; however, probing on depth and context was limited. The survey also asked participants to rate their health (excellent, very good, good, fair, poor) and other characteristics of patient's demographics, residence, access, and 
Table 1. Population Characteristics of Respondents to Survey From March 2016 to August 2017 Stratified by SelfReported Health Status

\begin{tabular}{|c|c|c|c|c|c|}
\hline & \multirow[b]{2}{*}{ Total } & \multicolumn{4}{|c|}{ Self-Reported Health } \\
\hline & & Excellent or Very Good & Good & Fair or Poor & $P$ value \\
\hline $\mathrm{N}$ & 166 & 41 & 71 & 54 & \\
\hline$\%$ & & 24.7 & 42.8 & 32.5 & \\
\hline \multicolumn{6}{|l|}{ Age categories (\%) } \\
\hline 65 to 74 years & 38.6 & 41.5 & 33.8 & 42.6 & .094 \\
\hline 75 to 84 years & 39.2 & 48.8 & 42.3 & 27.8 & \\
\hline 85 years and older & 22.3 & 9.8 & 23.9 & 29.6 & \\
\hline \multicolumn{6}{|l|}{ Race/ethnicity (\%) } \\
\hline $\mathrm{NH}$ white & 32.5 & 26.8 & 45.1 & 20.4 & .008 \\
\hline NH black & 34.9 & 34.1 & 36.6 & 33.3 & \\
\hline Hispanic & 27.1 & 31.7 & 12.7 & 42.6 & \\
\hline NH Other & 5.4 & 7.3 & 5.6 & 3.7 & \\
\hline \multicolumn{6}{|l|}{ Language at home (\%) } \\
\hline English only & 78.2 & 75.0 & 90.1 & 64.8 & .003 \\
\hline \multicolumn{6}{|l|}{ Education (\%) } \\
\hline$<$ High School & 16.3 & 19.5 & 18.3 & 11.1 & .825 \\
\hline High school graduate/GED & 36.7 & 31.7 & 35.2 & 42.6 & \\
\hline Some college & 33.1 & 31.7 & 32.4 & 35.2 & \\
\hline 4-year degree or more & 13.9 & 17.1 & 14.1 & 11.1 & \\
\hline Health literacy, inadequate & 34.3 & 26.8 & 29.6 & 46.3 & .076 \\
\hline \multicolumn{6}{|l|}{ Income (\%) } \\
\hline$<\$ 25,000$ & 51.2 & 51.2 & 54.9 & 46.3 & .594 \\
\hline$\$ 25,001$ to 50,000 & 22.9 & 26.8 & 15.5 & 29.6 & \\
\hline$>\$ 50,000$ & 18.1 & 14.6 & 19.7 & 18.5 & \\
\hline Income, unknown & 7.8 & 7.3 & 9.9 & 5.6 & \\
\hline Married (\%) & 41.0 & 48.8 & 33.8 & 44.4 & .245 \\
\hline Household size, mean \pm SD & $1.9(0.9)$ & $1.8(0.7)$ & $1.9(0.9)$ & $2.0(1.1)$ & .494 \\
\hline \multicolumn{6}{|l|}{ Cognitive status } \\
\hline Any impairment (\%) & 4.9 & 2.4 & 4.2 & 7.6 & .494 \\
\hline \multicolumn{6}{|l|}{ Functional impairment (\%) } \\
\hline ADL impairment & 23.5 & 14.6 & 21.1 & 33.3 & .085 \\
\hline IADL impairment & 40.4 & 24.4 & 36.6 & 57.4 & .004 \\
\hline \multicolumn{6}{|l|}{ Assistance device use (\%) } \\
\hline Independent, inside & 71.1 & 78.0 & 69.0 & 68.5 & .525 \\
\hline Independent, outside & 45.8 & 63.4 & 39.4 & 40.7 & .033 \\
\hline \multicolumn{6}{|l|}{ Insurance (\%) } \\
\hline Medicare & 88.0 & 87.8 & 91.5 & 83.3 & .376 \\
\hline Medicaid & 19.3 & 26.8 & 19.7 & 13.0 & .235 \\
\hline Other insurance & 54.2 & 48.8 & 59.2 & 51.9 & .520 \\
\hline \multicolumn{6}{|l|}{ Source(s) of care (\%) } \\
\hline Non-VHA provider & 62.0 & 65.9 & 63.4 & 57.4 & .670 \\
\hline \multicolumn{6}{|l|}{ Most of care } \\
\hline VHA & 78.3 & 85.4 & 73.2 & 79.6 & .207 \\
\hline Non-VHA & 21.1 & 12.2 & 26.8 & 20.4 & \\
\hline Unknown & 0.6 & 2.4 & 0.0 & 0.0 & \\
\hline \multicolumn{6}{|l|}{ Travel to clinic } \\
\hline Drive (\%) & 53.0 & 51.2 & 52.1 & 55.6 & .898 \\
\hline Travel time, minutes \pm SD & $33.3 \pm 21.3$ & $37.4 \pm 15.0$ & $33.9 \pm 24.3$ & $29.5 \pm 17.4$ & .328 \\
\hline
\end{tabular}

ALD, Activities of Daily Living; GED, general education degree, IADL, Independent Activities of Daily Living; NH, NonHispanic, SD, standard deviation; VHA, Veterans Health Administration. ${ }^{*} P<.05$. 
health (Table 1). If patients were unable to answer $(\mathrm{n}=6,3.4 \%)$, we included responses provided by the caretaker as access and health care use encompasses perceptions of the patient or caretaker. ${ }^{22}$

\section{Analysis}

We used qualitative content analysis to "provide knowledge and understanding of the phenomenon under study." ${ }^{23}$ A core team of 3 researchers and a trained research assistant, who delivered and recorded the surveys, analyzed responses in a multistep process. First, using an inductive, conventional approach, ${ }^{23,24}$ the research assistant reviewed all 177 participant responses and, with open coding, ${ }^{25}$ identified key terms and concepts of reasons for using both VHA and non-VHA care. The larger study team reviewed the initial findings and discerned that the terms and concepts aligned with Penchanksy and Thomas's framework of access, consisting of 5 relevant categories. ${ }^{26}$ To validate the categorization of the previously identified terms and concepts and increase the trustworthiness of the analysis, ${ }^{27}$ all responses were independently reviewed again by the research assistant and physician-researcher. Consistent with deductive, directed content analysis, ${ }^{23,24}$ all responses were classified into none, 1 , or more of the 5 categories of the framework. ${ }^{26}$ Coders were blinded to other participant information during this process. Inter-rater reliability between coders was $91 \%$. Researchers met independently and with the larger study team to resolve discrepancies of categorization by consensus.

In the final step, researchers examined the prevalence of each response category for salience ${ }^{28}$ and meaning, independently and across self-reported health status: "excellent/very good," "good," and "fair/poor." Self-reported health status serves as a proximal and relevant factor in health care use. ${ }^{29}$ Researchers assessed how the prevalence of each category mapped onto self-reported health to better understand if and how health status may explain reasons for VHA and non-VHA use.

Given the evidence that veterans of minority race and ethnicity face unique access barriers ${ }^{30,31}$ and prevalence among our study population, we performed a post hoc analysis of participants who identified as Hispanic or of a non-white race to evaluate if the concepts and categories for VHA and non-VHA use differed among this subpopulation.

\section{Results}

\section{Population Characteristics}

A total of 177 patients who used services at the Bronx VAMC and were identified as using nonVHA health care within the Bronx took the survey. One participant did not answer the question and 10 responses were unable to be categorized due to limited context and depth.

Of the 166 respondents, the majority were 75 years or older ( 75 to 84 years: $39.2 \%$; 85 or older: $22.3 \%$ ) with nearly half with functional mobility deficits: $23.5 \%$ reported at least 1 impairment of activities of daily living (ADL), 40.4\% reported at least 1 impairment with instrumental activities of daily living (IADL), and 54.2\% reporting using an assistive device outside the home. Only $4.9 \%$ were identified to have any cognitive impairment: 5 respondents with mild, 2 with moderate, and 1 with severe cognitive impairment. Nearly half (47\%) did not drive to the clinic. The average reported travel time to the Bronx VAMC was 33.4 (standard deviation, 21.3; median, 30; interquartile range, 20 to 45) minutes. Racial and ethnic (NH white, $32.5 \%$; NH black, 34.9\%; Hispanic, 27.1\%) and socioeconomic diversity was consistent with the Bronx VAMC population. Twenty-two percent spoke an additional language to English at home. Half reported an income less than $\$ 25000$. More than 1 in 3 of the respondents (34.3\%) screened positive for inadequate health literacy. Although 88.4\% reported having Medicare, $78.7 \%$ reported getting most of their care at the VHA (Table).

\section{Self-Reported Health}

When asked about health status, $24.7 \%$ reported their health as excellent or very good; $42.8 \%$, good; and $32.5 \%$, fair or poor. Across groups, patients reporting their health as fair or poor were more likely to be Hispanic, speak a non-English language at home, more likely to have IADL impairment, and use an assistive device outside their home (Table).

\section{Reasons for VHA and non-VHA Health Care Utilization}

We synthesized survey responses into common terms and concepts and identified alignment with Penchansky and Thomas' 5 categories of access: acceptability, accessibility, affordability, availability, and accommodation. ${ }^{26}$ 
Figure 1. Percentage of patients mentioning the categories of Acceptability, Accessibility, Affordability, Availability and Accommodation as reasons for using Veterans Affairs and non-Veterans Affairs services across self-reported health status. Self-reported health status categorized as excellent/very good (black bars), good (gray bars), and fair/poor (white bars). $* \boldsymbol{P}<.05$

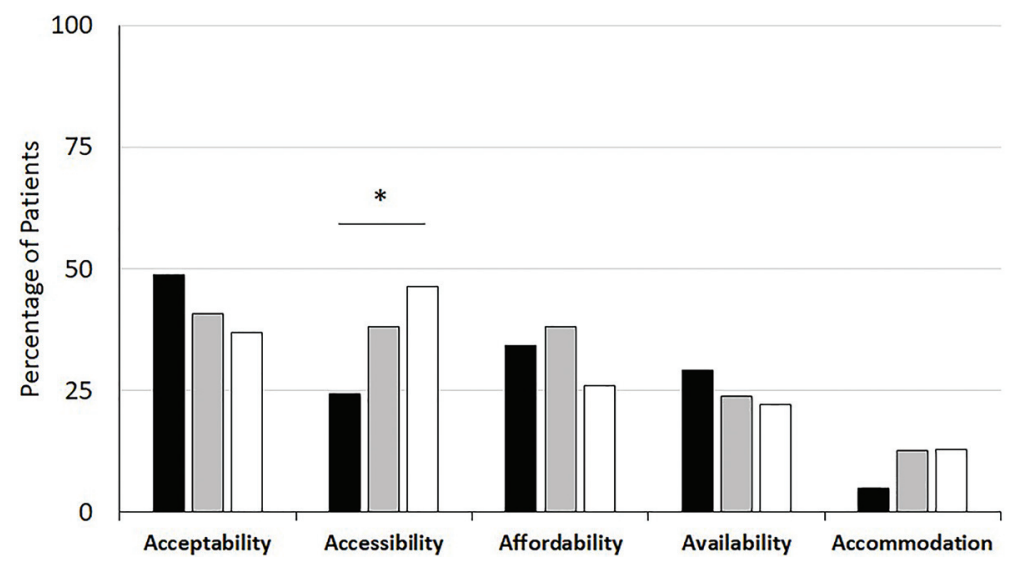

Acceptability, defined as the patient's perceptions about the personal and practice characteristics of the provider and providing system, was the most mentioned category by $44 \%$ of respondents and encompassed concepts of satisfaction, quality, continuity of care, and seeking second opinions. Respondents described the importance of relationships and maintaining care with the provider they know or who cared for them within or outside the VHA, notably if the relationship was established during a time of crisis. This is captured in 1 response: "The ambulance took me to [non-VHA hospital] because I had a heart attack and [I] stayed with that doctor who took care of me there. She is very efficient and took me out of that situation. I stayed with her care. She kept me under control." Others listed the duration of the relationship with providers, captured by a participant who said: "I've had non-VHA [primary care provider] for at least 20 years and I like him." A few participants also cited the desire for a second opinion for treatment.

Accessibility, defined as the proximity and ease of travel to care, was mentioned by $37 \%$ of participants, particularly in the context of urgent or emergency care. As 1 patient stated, and echoed by several others, "It is convenient for me to go to non-VHA for emergencies; it is closer."

Affordability, defined as the relationship between the price of care and the ability of patients to pay in the context of insurance and other benefits, as mentioned by $33 \%$ of respondents. Participants cited out-of-pocket costs for medications, copayments for visits, and benefits within the VHA related to their service-connected disability, and choosing location based on costs and coverage. A participant stated, "There are no payments here [...] on the outside it costs me. My medications are free here." Others commented on condition- and cost-specific choices based on conditions being service-connected and the degree of outside insurance coverage. One respondent said, "Anything connected to that disability gets covered here but my insurance has more coverage at non-VHA."

The least frequently mentioned dimensions were availability (25\%) and accommodation (11\%). When availability was mentioned, defined as the number and type of services available to address the needs of the patients, respondents described seeking out specialty and subspecialty care outside the VHA, such as cardiology and pulmonology services and cancer treatment. Accommodation is defined as the way services are organized and delivered to accommodate patient preferences, such as telephone availability, hours of operation, and wait-times for care, and encompassed concepts of timeliness and service alignment. Respondents mentioned the timeliness of same-day access to outside services and longer wait-times for procedures or tests within the VHA. Other respondents mentioned the preference of the " 1 stop shop" of the VHA. 


\section{Differences in Categories of Access across Self- Reported Health Status}

Within each of the 5 categories, content and tone of quotes did not consistently differ across selfreported health status (Appendix Table 1). However, the prevalence of the 5 categories of access differed across and between levels of selfreported health status (Figure 1).

Accessibility was mentioned more among respondents with poor self-reported health status. Although themes of accessibility were mentioned by only $24 \%$ of respondents with excellent or very good health, $46 \%$ of patients with fair or poor health mentioned accessibility $(P=.031)$, making it the most prevalent category among this group (Figure). One respondent, who reported poor health, cited the burden of travel, saying "Traveling is the main reason, I cannot handle it anymore." Notably, more participants with poor health status mentioned the theme of proximity regarding emergency services. Acceptability remained prominent and did not differ by self-reported health status (excellent/very good, 49\%; good, 41\%; fair/poor, $44 \% ; P=.45)$. Respondents consistently cited the importance of relationships and continuity of care after treatment across levels of health status (Appendix Table 1). Affordability, availability, and accommodation did not differ statistically or qualitatively across self-reported health status (Figure, Appendix Table 1).

\section{Respondents of Minority Race and Ethnicity}

Participants of minority race and ethnicity were younger (mean, 77.0 vs $\mathrm{NH}$ white 80.3 years, $P=.018)$, more likely to speak a language other than English at home (29.7 vs 5.6, $P<.001)$, less likely to have a non-VHA provider (55.4 vs $75.9, P=.011$ ), and more likely to rely on the VHA for most of their care (84.8 vs $64.8, P=.011)$. Further, respondents of minority race and ethnicity were more likely to be covered with Medicaid (24.1 vs 9.3, $P=.23$ ) and less likely to report Medicare coverage (83.9 vs 96.3, $P=.022$ ) (Appendix Tables 2-3).

When examining the categories of reasons for VHA and non-VHA use, respondents of minority race and ethnicity were less likely to mention acceptability (34.8\% vs NH white, $55.6 \%, P=.011)$, particularly among patients with poor or fair health (28\% vs $\mathrm{NH}$ white, $73 \% ; P=.006$ ). There was also a trend of increased mention of accessibility across health status by respondents of minority race and ethnicity (excellent or very good health $13 \%$ vs fair or poor health $49 \%, P=.005)$; a trend that did not occur in $\mathrm{NH}$ white respondents (Appendix Tables 4).

\section{Discussion}

We analyzed open-ended responses from veterans over 65 years from the Bronx VAMC who have used both VHA and non-VHA health care services to understand the reasons for dual system utilization among older, urban-dwelling veterans across levels of self-reported health status. Among 5 categories of access, acceptability remained prominent with no difference across health status, signifying the persistent importance of patient-provider relationships, continuity, and trust. Accessibility increased and became the most prominent category among participants with lower self-reported health status, which was driven by respondents of minority race and ethnicity. This highlights the burden of distance and travel to care as health declines, a potential contributor ongoing in health inequities. These findings build on prior research of dual system use by veterans and offer insight into how the VHA may reduce the consequences of care fragmentation and enhance care coordination for older vulnerable veteran populations.

In discrete choice experiments testing the preferences of timeliness, flexible appointments, continuity, and costs, older adults valued informational and relational continuity of care, especially for new and worrisome conditions, over other options. ${ }^{32-34}$ Through the implementation of the PatientAligned Care Team (PACT) and geriatric-specific care (Geri-PACT), the VHA has enhanced provider and team continuity. ${ }^{14,15,35}$ In addition, the VHA delivers effective home-based primary care with the continuity of multidisciplinary care teams for qualified older adults. ${ }^{36,37}$ These efforts and their benefits may add to reasons why more veterans are relying on the VHA for primary and specialty care services. ${ }^{11-13,38}$ Veterans, who experience higher provider continuity, also experience improved outcomes, lower ED visits, and hospitalizations. ${ }^{7,39}$ Similarly, greater continuity of the core primary care team of physicians, nurses, and medical assistants has been associated with improved performance, lower ED visits, particularly with medically complex patients. ${ }^{35}$

Distance has been a known factor influencing veteran reliance on VHA care. ${ }^{4,18}$ VHA policy has 
focused on distance with the CHOICE Act ${ }^{18}$ and recently adopted drive time (MISSION Act) ${ }^{40}$ on whether non-VHA services could be covered by the VHA. This focus is aimed to enhance access for rural veterans who may have closer non-VHA compared with VHA options. While disparities in access to care among rural veterans have been well documented, ${ }^{41}$ our findings highlight that distances in urban settings, though much shorter than rural settings, bears a significant burden, particularly as health status declines. Nearly $50 \%$ of our respondents did not drive, relying on other modalities to get care, including taxi and public transportation. Despite the extensive public transportation options within New York City and the Bronx, like other metropolitan cities, these transportation systems are geared toward travel in and out of economic hubs, which do not always align with health facilities' locations. ${ }^{42-44}$ The VHA provides benefits through the Veterans Transportation Services (VTS) for door-to-door transportation via hired taxi or para-transport services for qualifying Veterans; however, the availability, capacity, and responsiveness of these local programs may not overcome the barriers to accessing care among patients with declining health.

We observed the prominence of accessibility not only among a vulnerable population of older adults with worse self-reported health but also during vulnerable times of emergent care. As a result, the use of closer non-VHA care in settings of emergency may precipitate care fragmentation, disrupting the continuity that patients desire and may provide greater benefit. ${ }^{7,8}$ In addition, as we observed, the use of closer non-VHA care in times of emergency for new illnesses may encourage older veterans who value continuity to make and then maintain their specialty care with non-VHA providers. While the VHA has implemented enhanced coordination and continuity within the VHA system, the enhancement of VHA and non-VHA care coordination and communication needs improvement ${ }^{45,46}$ and may help facilitate better care or return to the VHA. ${ }^{14}$

The less frequently mentioned domains of availability, affordability, and accommodation are consistent with higher prioritization of continuity and thoroughness of care. ${ }^{32,33}$ Further, the increased reliance on VHA for specialty care, ${ }^{11}$ low out-of-pocket costs due to copayment exemption or a service-connected disability, ${ }^{4,19}$ and improved VHA wait-times ${ }^{47}$ signify a closing gap between VHA and the private sector, ${ }^{11,12}$ and decreasing significance when choosing care.

Taken together, our findings should be interpreted in the context of our patient population and the VHA policies aiming to enhance access and care. This urban, minority population cited distance (accessibility) and relationships (acceptability) as primarily shaping where they choose to receive care. Nationally, more than 3 million people who are older, lower socioeconomic status, and from an ethnic minority group experience transportation barriers to care. ${ }^{48}$ The veterans relying on the VHA are more likely to be socioeconomically disadvantaged and more medically complex with worse self-reported health. ${ }^{12}$ Implementation of PACT and other VHA efforts to enhance continuity may improve the care for this socioeconomically and medically complex population. However, as patients' health diminishes and medical events occur, patients prefer to use more proximal (potentially non-VHA) facilities, particularly for urgent, emergency, specialty, and surgical care. ${ }^{11,49}$ VHA policies enacted as a result of CHOICE and MISSION Act legislation adopted objective measures of drive times and wait-times, which may not account for the burden of travel experienced by veterans in urban environments, especially as their health declines and needs increase.

The call to transition from measures of travel time and distance to individual clinical needs and preferences with greater integration and coordination with non-VHA providers merits consideration. ${ }^{50}$ Real-time health information exchange and care coordination between VHA and non-VHA health systems may facilitate greater continuity and reduction in adverse events. ${ }^{17,51,52}$

The recent expansion of telehealth may reduce the need and burden of travel for an in-person evaluation. $^{53}$ Alternatively, the VHA may improve transportation options to maintain VHA continuity. These options include improved logistic collaboration with municipal-sponsored or private transportation options ${ }^{48,54}$ and enhanced access to Veteran Transportation Services ${ }^{55}$ for older patients with declining health. These options are available and feasible in urban settings and are variably implemented across VHA Medical Centers. Evaluation and sharing of best practices are needed. Expansion of these services should be weighed against care fragmentation, outcomes, and costs of the VHA covering closer non-VHA services. 


\section{Limitations}

First, these responses come from a single institution and geographic region which may limit generalizability. Second, the researcher recording the survey responses was VHA-based; despite an emphasis on anonymity and neutrality, respondents may have been apprehensive to make negative comments toward the VHA, limiting our ability to understand some dimensions of their care-seeking decisions. Third, responses were manually rather than audiorecorded, which may have reduced accuracy; however, the same researcher recorded all the responses so there was consistency across the sample. Fourth, there was limited probing which may have elucidated further reasoning and confirmed the reference (VHA or non-VHA) of responses; however, the researcher recorded the responses in real-time and captured the full response with the terms used by the respondents.

\section{Conclusion}

By examining the reasons why older, veterans in an urban environment choose VHA and non-VHA care, we identified that acceptability, embodied in the patient-provider relationship which may be forged during urgent or emergent care, remains constant, while accessibility intensifies as selfreported health declines. Reducing transportation barriers for older veterans to get to the providers that they trust within or outside the VHA and enhancing integration and coordination, may serve to improve outcomes and satisfaction and reduce inequities for a growing vulnerable population within the VHA.

To see this article online, please go to: http://jabfm.org/content/ 34/2/291.full.

\section{References}

1. Z Joan Wang PD, Melissa Cidade PD, Michael Larsen PD, Pearman G, Schimpf M, Pavan Dhanireddy PD. 2018 Survey of Veteran Enrollees' Health and Use of Health Care Data Findings Report. Rockville, MD: Strategic Analysis Service, Office of Strategic Planning and Analysis; 2019:1202.

2. Wong ES, Liu C-F, Hernandez SE, et al. Longer wait times affect future use of VHA primary care. Healthc (Amst) 2018;6:180-5.

3. Zhu CW, Penrod JD, Ross JS, Dellenbaugh C, Sano M. Use of Medicare and Department of Veterans Affairs health care by veterans with dementia: a longitudinal analysis. J Am Geriatr Soc 2009;57:1908-14.

4. Hynes DM, Koelling K, Stroupe K, et al. Veterans' access to and use of Medicare and Veterans Affairs health care. Med Care 2007;45:214-23.

5. Pizer SD, Gardner JA. Is fragmented financing bad for your health? Inquiry 2011;48:109-22.

6. Chaiyachati KH, Gordon K, Long $\mathrm{T}$, et al. Continuity in a VA patient-centered medical home reduces emergency department visits. PLoS ONE 2014;9:e96356.

7. Katz DA, McCoy KD, Vaughan-Sarrazin MS. Does greater continuity of veterans administration primary care reduce emergency department visits and hospitalization in older veterans? J Am Geriatr Soc 2015;63:2510-8.

8. Kern LM, Seirup JK, Rajan M, Jawahar R, Stuard SS. Fragmented ambulatory care and subsequent healthcare utilization among Medicare beneficiaries. Am J Manag Care 2018;24:e278-e284.

9. Nyweide DJ, Anthony DL, Bynum JPW, et al. Continuity of care and the risk of preventable hospitalization in older adults. JAMA Intern Med 2013;173:1879-85.

10. Thorpe JM, Thorpe CT, Schleiden L, et al. Association between dual use of Department of Veterans Affairs and Medicare Part D drug benefits and potentially unsafe prescribing. JAMA Intern Med July 2019;179:1584.

11. Liu C-F, Batten A, Wong ES, Fihn SD, Hebert PL. Fee-for-service Medicare-enrolled elderly veterans are increasingly voting with their feet to use more VA and less Medicare, 2003-2014. Health Serv Res 2018;53 Suppl 3:5140-58.

12. Hebert PL, Batten AS, Gunnink E, et al. Reliance on Medicare Providers by Veterans after Becoming Age-Eligible for Medicare is Associated with the Use of More Outpatient Services. Health Serv Res 2018;53 Suppl 3:5159-80.

13. Nelson KM, Helfrich C, Sun H, et al. Implementation of the patient-centered medical home in the Veterans Health Administration: associations with patient satisfaction, quality of care, staff burnout, and hospital and emergency department use. JAMA Intern Med 2014;174:1350-8.

14. Rosland A-M, Nelson K, Sun H, et al. The patientcentered medical home in the Veterans Health Administration. Am J Manag Care 2013;19:e263e272.

15. Sullivan JL, Eisenstein R, Price T, Solimeo S, Shay K. Implementation of the geriatric patient-aligned care team model in the Veterans Health Administration (VA). J Am Board Fam Med 2018;31:456-65.

16. Kullgren JT, Fagerlin A, Kerr EA. Completing the MISSION: a blueprint for helping veterans make the most of new choices. J Gen Intern Med 2020;35:1567-4. 
17. Mattocks KM, Cunningham K, Elwy AR, et al. Recommendations for the evaluation of cross-system care coordination from the VA state-of-the-art working group on VA/Non-VA Care. J Gen Intern Med 2019;34:18-23. (Suppl).

18. Stroupe KT, Martinez R, Hogan TP, et al. Experiences with the veterans' choice program. J Gen Intern Med 2019;34:2141-9.

19. Wong ES, Maciejewski ML, Hebert PL, Reddy A, Liu C-F. Predicting primary care use among patients in a large integrated health system: the role of patient experience measures. Med Care 2019;57:608-14.

20. Dixon BE, Schwartzkopf AL, Guerrero VM, et al. Regional data exchange to improve care for veterans after non-VA hospitalization: a randomized controlled trial. BMC Med Inform Decis Mak 2019;19:125-13.

21. Bronx Regional Health Information Organization. Bronx RHIO: Connecting for Better Health. Bronx, NY; 2019.

22. Qualls SH. Caregiving families within the longterm services and support system for older adults. Am Psychol 2016;71:283-93.

23. Hsieh H-F, Shannon SE. Three approaches to qualitative content analysis. Qual Health Res 2005; 15:1277-88.

24. Elo S, Kyngäs H. The qualitative content analysis process. J Adv Nurs 2008;62:107-15.

25. Saldana J. The Coding Manual for Qualitative Researchers. Third Edition. Los Angeles: SAGE; 2015.

26. Penchansky R, Thomas JW. The concept of access: definition and relationship to consumer satisfaction. Med Care 1981;19:127-40.

27. Elo S, Kääriäinen $M$, Kanste $O$, Pölkki $T$, Utriainen K, Kyngäs H. Qualitative content analysis: a focus on trustworthiness. SAGE Open January 2014;4:215824401452263-10.

28. Buetow S. Thematic analysis and its reconceptualization as 'saliency analysis'. J Health Serv Res Policy 2010;15:123-5.

29. Rosenstock IM, Strecher VJ, Becker MH. Social learning theory and the Health Belief Model. Health Educ Q 1988;15:175-83.

30. Augustine MR, Nelson KM, Fihn SD, Wong ES. How are patients accessing primary care within the patient-centered medical home? Results from the Veterans Health Administration. J Ambul Care Manage 2018;41:194-203.

31. Jones AL, Mor MK, Cashy JP, et al. Racial/ethnic differences in primary care experiences in patientcentered medical homes among veterans with mental health and substance use disorders. J Gen Intern Med 2016;31:1435-43.

32. Cheraghi-Sohi S, Hole AR, Mead N, et al. What patients want from primary care consultations: a discrete choice experiment to identify patients' priorities. Ann Fam Med 2008;6:107-15.
33. Rubin G, Bate A, George A, Shackley P, Hall N. Preferences for access to the GP: a discrete choice experiment. Br J Gen Pract 2006;56:743-8.

34. Turner D, Tarrant C, Windridge K, et al. Do patients value continuity of care in general practice? An investigation using stated preference discrete choice experiments. J Health Serv Res Policy 2007;12:132-7.

35. Crawford ER, Reeves CJ, Stewart GL, Astrove SL. To link or not to link? Multiple team membership and unit performance. J Appl Psychol 2019;104:34156.

36. Gillespie SM, Manheim C, Gilman C, et al. Interdisciplinary team perspectives on mental health care in VA home-based primary care: a qualitative study. Am J Geriatr Psychiatry 2019;27:128-37.

37. Edwards ST, Prentice JC, Simon SR, Pizer SD. Home-based primary care and the risk of ambulatory care-sensitive condition hospitalization among older veterans with diabetes mellitus. JAMA Intern Med 2014;174:1796-803.

38. Schuttner L, Reddy A, Rosland A-M, Nelson K, Wong ES. Association of the implementation of the patient-centered medical home with quality of life in patients with multimorbidity. October 2019;1-7.

39. Reddy A, Wong E, Canamucio A, et al. Association between continuity and team-based care and health care utilization: an observational study of Medicareeligible veterans in VA patient aligned care team. Health Serv Res 2018;53:5201-118.

40. U.S. Department of Veterans Affairs. VA launches new health care options under MISSION Act. www. va.gov. https://www.va.gov/opa/pressrel/pressrelease. cfm?id=5264. Published June 6, 2019. Accessed February 5, 2020.

41. Kondo K, Low A, Everson T, et al. Health disparities in veterans: a map of the evidence. Med Care 2017;55 Suppl 9 Suppl 2:S9-S15. Suppl 9 Suppl 2.

42. Silver D, Blustein J, Weitzman BC. Transportation to clinic: findings from a pilot clinic-based survey of low-income suburbanites. J Immigr Minor Health 2012;14:350-5.

43. National Academies of Sciences, Engineering, and Medicine, Transportation Research Board, Health and Medicine Division, Board on Population Health and Public Health Practice. Exploring data and metrics of value at the intersection of health care and transportation: Proceedings of a Workshop. Wizemann T, Baciu A, eds. November 2016.

44. Locatelli SM, Sharp LK, Syed ST, Bhansari S, Gerber BS. Measuring health-related transportation barriers in urban settings. J Appl Meas 2017;18:178-93.

45. Schlosser J, Kollisch D, Johnson D, Perkins T, Olson A. VA-community dual care: veteran and clinician perspectives. J Community Health 2020;45:795802.

46. Nevedal AL, Wagner TH, Ellerbe LS, Asch SM, Koenig CJ. a qualitative study of primary care 
providers' experiences with the veterans choice program. J Gen Intern Med 2019;34:598-603.

47. Penn M, Bhatnagar S, Kuy S, et al. Comparison of wait times for new patients between the private sector and United States Department of Veterans Affairs Medical Centers. JAMA Netw Open 2019;2:e187096.

48. Syed ST, Gerber BS, Sharp LK. Traveling towards disease: transportation barriers to health care access. J Community Health 2013;38:976-93.

49. Yoon J, Vanneman ME, Dally SK, Trivedi AN, Phibbs CS. Veterans' reliance on VA care by type of service and distance to va for nonelderly VA-Medicaid dual enrollees. Med Care January 2019.

50. Shulkin D. Implications for veterans' health care: the danger becomes clearer. JAMA Intern Med July 2019; 179:1586.
51. Dixon BE, Haggstrom DA, Weiner M. Implications for informatics given expanding access to care for Veterans and other populations. J Am Med Inform Assoc 2015;22:917-20.

52. Unruh MA, Jung H-Y, Kaushal R, Vest JR. Hospitalization event notifications and reductions in readmissions of Medicare fee-for-service beneficiaries in the Bronx, New York. J Am Med Inform Assoc 2016;2:ocw139-7.

53. Baum A, Kaboli PJ, Schwartz MD. Reduced in-person and increased telehealth outpatient visits during the COVID-19 pandemic. Ann Intern Med August 2020;174:129-31:M20-M3026.

54. Powers BW, Rinefort S, Jain SH. Nonemergency medical transportation: delivering care in the era of lyft and uber. JAMA 2016;316:921-2.

55. Department of Veterans Affairs. Veterans transportation service. final rule. Fed Regist 2016;81. 
Appendix Table 1: Exemplar Responses From Veterans for Using Veterans Affairs and Non-Veterans Affairs Care Across 5 Dimensions of Access Stratified by Self-Reported Health Status

\begin{tabular}{|c|c|c|c|}
\hline \multirow[b]{2}{*}{ Category } & \multicolumn{3}{|c|}{ Self-Reported Health Status } \\
\hline & Excellent or Very Good & Good & Fair or Poor \\
\hline Acceptability & $\begin{array}{l}\text { - (Satisfaction) "Only because } \\
\text { cardiologist, non-VHA put in my } \\
\text { pacemaker. He knows me well; he } \\
\text { saved my life. I feel comfortable } \\
\text { with his care." } \\
\text { - (Relationship) "I've been in the } \\
\text { VHA for } 40 \text { years." }\end{array}$ & $\begin{array}{l}\text { - (Satisfaction) "I had a MI, } \\
\text { brought to the Hospital, kept the } \\
\text { Cardiologist since then because } \\
\text { he more or less saved my life." } \\
\text { - (Relationship) "I've had non- } \\
\text { VHA PCP for at least } 20 \text { years, } \\
\text { and I like him." }\end{array}$ & $\begin{array}{l}\text { - (Satisfaction) "[I] went to [outside } \\
\text { hospital]. EMS took me there. I } \\
\text { had a heart attack [...] She is very } \\
\text { efficient [...]. I stayed with her } \\
\text { care. She kept me under control." } \\
\text { - (Relationship) "My non-VHA } \\
\text { PCP has been my doctor for } \\
40 \text { years [...]" }\end{array}$ \\
\hline Accessibility & $\begin{array}{l}\text { - (Proximity) "If I can't make it to } \\
\text { the VHA, the non-VHA is closer. } \\
\text { Go to non-VHA for minor } \\
\text { things" } \\
\text { - (Travel burden) “Convenience, } \\
\text { location. Aging, I drive but maybe } \\
\text { my car isn't safe, and I don't } \\
\text { intend to replace it, so } \\
\text { transportation will be in } \\
\text { question." }\end{array}$ & $\begin{array}{l}\text { - (Proximity) "Having assurance of } \\
\text { having someone close if } \\
\text { something happens..." } \\
\text { - (Proximity for emergent care) "If } \\
\text { something is wrong, I will come } \\
\text { here but EMS would have to } \\
\text { bring me to the nearest hospital" }\end{array}$ & $\begin{array}{l}\text { - (Proximity) "The non-VHA } \\
\text { doctor and hospital is } 3 \text { blocks } \\
\text { from my house. It's very close. } \\
\text { He is a good doctor." } \\
\text { - (Travel burden) "Traveling is } \\
\text { main reason. I can't handle it } \\
\text { anymore." }\end{array}$ \\
\hline Affordability & $\begin{array}{l}\text { - (VHA Benefits) "Because I served, } \\
\text { the VHA is more convenient. I } \\
\text { have no insurance except } \\
\text { Medicare." } \\
\text { - (Out-pocket costs) "Starting to } \\
\text { come here [VHA] now because of } \\
\text { the payments." }\end{array}$ & $\begin{array}{l}\text { - (Costs, out-of-pocket) "There are } \\
\text { no payments here [VHA]. On the } \\
\text { outside, it costs me. My } \\
\text { medications are free here [...]." } \\
\text { - (Costs) "Prefer VHA now } \\
\text { especially because cost increasing } \\
\text { outside as I get older." }\end{array}$ & $\begin{array}{l}\text { - (Costs, Medications) } \\
\text { "Medications cost too much so I } \\
\text { will start coming here to the } \\
\text { VHA" } \\
\text { - (Costs, Medications) "Now the } \\
\text { specialists and the medicine are } \\
\text { free at the VHA." }\end{array}$ \\
\hline Availability & $\begin{array}{l}\text { - (Specialty services) "Chiropractor } \\
\text { is non-VHA because can't get one } \\
\text { here at the VHA and can't get a } \\
\text { referral for the chiropractor here. } \\
\text { Also, Dental is non-VHA because } \\
\text { can't get one here." }\end{array}$ & $\begin{array}{l}\text { - (Choice of services) "I have a vast } \\
\text { array of choices for providers and } \\
\text { services at non-VHA" }\end{array}$ & $\begin{array}{l}\text { - (Specific services) "I use the VHA } \\
\text { for specific reasons like } \\
\text { optometry and service-related } \\
\text { benefits." }\end{array}$ \\
\hline Accommodation & $\begin{array}{l}\text { - Wait-time) "Because I have the } \\
\text { insurance I use outside doctor, I } \\
\text { know it gets busy in here. I let the } \\
\text { other guys use the VHA." }\end{array}$ & $\begin{array}{l}\text { - (Wait-time) "I can get an } \\
\text { immediate appointment with my } \\
\text { non-VHA primary." } \\
\text { - (Wait-time) "After finding out I } \\
\text { had cancer, VHA would make me } \\
\text { wait } 2 \text { weeks for MRI so contacted } \\
\text { my pulmonologist and went to } \\
\text { [non-VHA hospital]." }\end{array}$ & $\begin{array}{l}\text { - (One stop shop) "Everything is } \\
\text { cohesive as far as the specialty } \\
\text { doctors being all here" } \\
\text { - (Wait-time) "Non-VHA for } \\
\text { quicker treatment and } \\
\text { emergencies" }\end{array}$ \\
\hline
\end{tabular}

VHA, Veterans Health Administration; MRI, magnetic resonance imaging; PCP, primary care physician; EMS, emergency medical services. 


\begin{tabular}{|c|c|c|c|c|c|}
\hline & \multirow[b]{2}{*}{ Total } & \multicolumn{4}{|c|}{ Self-Reported Health } \\
\hline & & Excellent or Very Good & Good & Fair or Poor & $P$ value \\
\hline $\mathrm{N}$ & 112 & 30 & 39 & 43 & \\
\hline$\%$ & & 26.8 & 34.8 & 38.4 & \\
\hline \multicolumn{6}{|l|}{ Age categories (\%) } \\
\hline 65 to 74 years & 43.8 & 46.7 & 43.6 & 41.9 & \multirow[t]{3}{*}{.276} \\
\hline 75 to 84 years & 35.7 & 43.3 & 38.5 & 27.9 & \\
\hline 85 years and older & 20.5 & 10.0 & 17.9 & 30.2 & \\
\hline \multicolumn{6}{|l|}{ Race/ethnicity (\%) } \\
\hline $\mathrm{NH}$ black & 51.8 & 46.7 & 66.7 & 41.9 & \multirow[t]{3}{*}{.077} \\
\hline Hispanic & 40.2 & 43.3 & 23.1 & 53.5 & \\
\hline Other & 8.0 & 10.0 & 10.3 & 4.7 & \\
\hline \multicolumn{6}{|l|}{ Language at home (\%) } \\
\hline English only & 70.3 & 65.5 & 87.2 & 58.1 & $.013^{*}$ \\
\hline \multicolumn{6}{|l|}{ Education (\%) } \\
\hline$<$ High School & 17.9 & 23.3 & 17.9 & 14.0 & \multirow[t]{4}{*}{.860} \\
\hline High school graduate/GED & 41.1 & 36.7 & 41.0 & 44.2 & \\
\hline Some college & 29.5 & 23.3 & 30.8 & 32.6 & \\
\hline 4-year degree or more & 11.6 & 16.7 & 10.3 & 9.3 & \\
\hline Health literacy, inadequate & 37.5 & 26.7 & 38.5 & 44.2 & .311 \\
\hline \multicolumn{6}{|l|}{ Income (\%) } \\
\hline$<\$ 25000$ & 55.4 & 56.7 & 59.0 & 51.2 & \multirow[t]{4}{*}{.547} \\
\hline$\$ 25001$ to 50000 & 20.5 & 20.0 & 15.4 & 25.6 & \\
\hline$>\$ 50000$ & 19.6 & 13.3 & 23.1 & 20.9 & \\
\hline Income, unknown & 4.5 & 10.0 & 2.6 & 2.3 & \\
\hline Married (\%) & 44.6 & 53.3 & 35.9 & 46.5 & .335 \\
\hline Household size, mean \pm SD & $2.0 \pm 0.9$ & $1.9 \pm 0.7$ & $1.9 \pm 0.88$ & $2.1 \pm 1.1$ & .533 \\
\hline \multicolumn{6}{|l|}{ Cognitive status } \\
\hline Any impairment (\%) & 4.5 & 3.3 & 2.6 & 7.0 & .590 \\
\hline \multicolumn{6}{|l|}{ Functional impairment (\%) } \\
\hline ADL impairment & 20.5 & 13.3 & 20.5 & 25.6 & .444 \\
\hline IADL impairment & 39.3 & 20.0 & 35.9 & 55.8 & .007 \\
\hline \multicolumn{6}{|l|}{ Assistance device use (\%) } \\
\hline Independent, inside & 70.5 & 76.7 & 71.8 & 65.1 & .554 \\
\hline Independent, outside & 48.2 & 60.0 & 51.3 & 37.2 & .142 \\
\hline \multicolumn{6}{|l|}{ Insurance (\%) } \\
\hline Medicare & 83.9 & 86.7 & 87.2 & 79.1 & .542 \\
\hline Medicaid & 24.1 & 36.7 & 28.2 & 11.6 & $.037^{*}$ \\
\hline Other insurance & 51.8 & 53.3 & 53.8 & 48.8 & .885 \\
\hline \multicolumn{6}{|l|}{ Source(s) of care (\%) } \\
\hline Non-VHA provider & 55.4 & 60.0 & 56.4 & 51.2 & .746 \\
\hline \multicolumn{6}{|l|}{ Most of care } \\
\hline VHA & 84.8 & 86.7 & 76.9 & 90.7 & .210 \\
\hline Non-VHA & 15.2 & 13.3 & 23.1 & 9.3 & \\
\hline Unknown & 0.0 & 0.0 & 0.0 & 0.0 & \\
\hline \multicolumn{6}{|l|}{ Travel to clinic } \\
\hline Drive (\%) & 49.1 & 50.0 & 46.2 & 51.2 & .897 \\
\hline Travel time, minutes $\pm \mathrm{SD}$ & $35 \pm 22$ & $39 \pm 10$ & $36 \pm 26$ & $31 \pm 18$ & .381 \\
\hline
\end{tabular}

ALD, Activities of Daily Living; GED, general education degree; IADL, Independent Activities of Daily Living; NH, NonHispanic; SD, standard deviation; VHA, Veterans Health Administration.

${ }^{*} P<.05$. 


\begin{tabular}{|c|c|c|c|c|c|}
\hline & \multirow[b]{2}{*}{ Total } & \multicolumn{4}{|c|}{ Self-Reported Health } \\
\hline & & Excellent or Very Good & Good & Fair or Poor & $P$ value \\
\hline $\mathrm{N}$ & 54 & 11 & 32 & 11 & \\
\hline$\%$ & & 20.4 & 59.3 & 20.4 & \\
\hline \multicolumn{6}{|l|}{ Age categories (\%) } \\
\hline 65 to 74 years & 27.8 & 27.3 & 21.9 & 45.5 & \multirow[t]{3}{*}{.522} \\
\hline 75 to 84 years & 46.3 & 63.6 & 46.9 & 27.3 & \\
\hline 85 years and older & 25.9 & 9.1 & 31.3 & 27.3 & \\
\hline \multicolumn{6}{|l|}{ Race/ethnicity (\%) } \\
\hline NH white & 100.0 & NA & NA & NA & \\
\hline \multicolumn{6}{|l|}{ Language at home (\%) } \\
\hline English only & 94.4 & 100.0 & 93.8 & 90.9 & .625 \\
\hline \multicolumn{6}{|l|}{ Education (\%) } \\
\hline$<$ High School & 13.0 & 9.1 & 18.8 & 0.0 & \multirow[t]{5}{*}{.686} \\
\hline High school graduate/GED & 27.8 & 18.2 & 28.1 & 36.4 & \\
\hline Some college & 40.7 & 54.5 & 34.4 & 45.5 & \\
\hline 4-year degree or more & 18.5 & 18.2 & 18.8 & 18.2 & \\
\hline Health literacy, inadequate & 27.8 & 27.3 & 18.8 & 54.5 & \\
\hline \multicolumn{6}{|l|}{ Income $(\%)$} \\
\hline$<\$ 25000$ & 42.6 & 36.4 & 50.0 & 27.3 & \multirow[t]{4}{*}{.262} \\
\hline$\$ 25001$ to 50000 & 27.8 & 45.5 & 15.6 & 45.5 & \\
\hline$>\$ 50000$ & 14.8 & 18.2 & 15.6 & 9.1 & \\
\hline Income, unknown & 14.8 & 0.0 & 18.8 & 18.2 & \\
\hline Married (\%) & 33.3 & 36.4 & 31.3 & 36.4 & .926 \\
\hline Household size, mean \pm SD & $1.7 \pm 0.9$ & $1.5 \pm 0.5$ & $1.8 \pm 1.0$ & $1.7 \pm 0.8$ & .468 \\
\hline \multicolumn{6}{|l|}{ Cognitive status } \\
\hline Any impairment (\%) & 5.7 & 0.0 & 6.3 & 10.0 & .596 \\
\hline \multicolumn{6}{|l|}{ Functional impairment (\%) } \\
\hline ADL impairment & 29.6 & 18.2 & 21.9 & 63.6 & $.021^{*}$ \\
\hline IADL impairment & 42.6 & 36.4 & 37.5 & 63.6 & .286 \\
\hline \multicolumn{6}{|l|}{ Assistance device use (\%) } \\
\hline Independent, inside & 72.2 & 81.8 & 65.6 & 81.8 & .427 \\
\hline Independent, outside & 40.7 & 72.7 & 25.0 & 54.5 & $.012^{*}$ \\
\hline \multicolumn{6}{|l|}{ Insurance (\%) } \\
\hline Medicare & 96.3 & 90.9 & 96.9 & 100.0 & .510 \\
\hline Medicaid & 9.3 & 0.0 & 9.4 & 18.2 & .339 \\
\hline Other insurance & 59.3 & 36.4 & 65.6 & 63.6 & .222 \\
\hline \multicolumn{6}{|l|}{ Source(s) of care (\%) } \\
\hline Non-VHA provider & 75.9 & 81.8 & 71.9 & 81.8 & .703 \\
\hline \multicolumn{6}{|l|}{ Most of care } \\
\hline VHA & 64.8 & 81.8 & 68.8 & 36.4 & $.030^{*}$ \\
\hline Non-VHA & 33.3 & 9.1 & 31.3 & 63.6 & \\
\hline Unknown & 1.9 & 9.1 & 0.0 & 0.0 & \\
\hline \multicolumn{6}{|l|}{ Travel to clinic } \\
\hline Drive (\%) & 61.1 & 54.5 & 59.4 & 72.7 & .649 \\
\hline Travel time, minutes \pm SD & $30 \pm 20$ & $36 \pm 15$ & $32 \pm 22$ & $22 \pm 12$ & .283 \\
\hline
\end{tabular}

ALD, Activities of Daily Living; GED, general education degree, IADL, Independent Activities of Daily Living; NA, not applicable; NH, Non-Hispanic, SD, standard deviation; VHA, Veterans Health Administration.

${ }^{*} P<.05$. 
Appendix Table 4: Categories of Reasons for Veteran Affairs and Non-Veteran Health Administration Use Across Self-Reported Health Status for Non-Hispanic White Respondents and Respondents of Other Races and Ethnicities

\begin{tabular}{|c|c|c|c|c|c|}
\hline & Total & Excellent or Very Good & Good & Fair or Poor & $P$ value \\
\hline NH-white, N (\%) & 54 & $11(20)$ & $32(59)$ & $11(20)$ & \\
\hline Other, N (\%) & 112 & $30(27)$ & $39(35)$ & $43(38)$ & \\
\hline \multicolumn{6}{|l|}{ Acceptability (\%) } \\
\hline NH-white & 55.6 & 54.5 & 50.0 & 72.7 & .424 \\
\hline Other & 34.8 & 46.7 & 33.3 & 27.9 & .247 \\
\hline \multicolumn{6}{|l|}{ Accessibility (\%) } \\
\hline NH-white & 37.0 & 54.5 & 31.3 & 36.4 & .385 \\
\hline Other* & 37.5 & $13.3^{*}$ & $43.6^{*}$ & $48.8^{*}$ & $.005^{*}$ \\
\hline \multicolumn{6}{|l|}{ Affordability (\%) } \\
\hline NH-white & 25.9 & 18.2 & 34.4 & 9.1 & .206 \\
\hline Other & 36.6 & 40.0 & 41.0 & 30.2 & .541 \\
\hline \multicolumn{6}{|l|}{ Availability (\%) } \\
\hline NH-white & 27.8 & 54.5 & 18.8 & 27.3 & .073 \\
\hline Other & 23.2 & 20.0 & 28.2 & 20.9 & .656 \\
\hline \multicolumn{6}{|c|}{ Accommodation (\%) } \\
\hline NH-white & 11.1 & 9.1 & 12.5 & 9.1 & .926 \\
\hline Other & 10.7 & 3.3 & 12.8 & 14.0 & .307 \\
\hline
\end{tabular}

NH, Non-Hispanic.

${ }^{*} P<.05$. 